\title{
ENSAYO DE INFLAMABILIDAD DE TEJAS ELABORADAS A PAR- TIR DE CAUCHO Y POLIETILENO RECICLADOS
}

Lucas E. Peisino, Rosana Gaggino, Jerónimo Kreiker, María Paz Sánchez Amono, Ricardo Arguello. Centro Experimental de La Vivienda Económica (CEVE-CONICET), Asociación Vivienda Económica (AVE), Córdoba - Argentina. Igualdad 3585 X5003BHG. http://www.ceve.org.ar http://www.ave.org.ar, +54 0351 4894442.nuevosmateriales@ceve.org.ar

Palabras clave: residuos, reciclado, sustentabilidad, ignición.

\section{Resumen:}

Este trabajo es sobre el mejoramiento de un componente constructivo desarrollado en el Centro Experimental de Vivienda Económica, en su comportamiento frente al fuego. Dicho componente es una teja elaborada con caucho y polietileno reciclados, la cual es fabricada por un proceso de termo-moldeo con presión.

El desarrollo de esta teja tuvo como objetivo colaborar en la reducción de estos residuos, que se acumulan en los basurales, produciendo contaminación. Se obtuvo un componente constructivo a base de residuos apto para construcciones de cubiertas inclinadas con estructura de madera, con ventajas desde los puntos de vista ecológicos, técnicos y económicos. La ventaja desde el punto de vista ecológico es que se utilizan residuos, en lugar de materias primas no renovables. Desde el punto de vista técnico, son tejas más livianas, más resistentes a la flexión, a la heladicidad y al impacto duro que las tradicionales. Por último, las ventajas desde el punto de vista económico son que su costo es menor que el de las tejas cerámicas esmaltadas de color negro existentes en el mercado, las más parecidas a las tejas desarrolladas; y que se reducen gastos de enterramiento de residuos a los municipios.

El principal problema a superar en el desarrollo de este componente fue su escasa resistencia al fuego, puesto que es conocido que tanto el caucho como el polietileno son materiales de fácil combustibilidad. Esta investigación permitió determinar cuáles son los recubrimientos con aditivos retardantes de llama más eficaces para que el componente sea considerado como un material apto desde este punto de vista según la Norma IEC 60695-2-11, denominada Ensayo del Filamento Incandescente.

Se evaluaron siete tipo de formulaciones: la primera de ellas sin tratamiento de aditivos retardantes de llama (mezcla patrón) y las seis restantes con los siguientes recubrimientos superficiales: esmalte sintético negro mezclado con polvo de bórax, esmalte sintético negro mezclado con polvo de residuos del pulido de porcelanato, revoque plástico fino flexible marca Revear (compuesto por resinas acrílicas, aditivos plastificantes, pigmentos y cargas minerales), pintura intumescente marca Venier; esmalte sintético negro mezclado con arena y por último esmalte sintético negro mezclado con el polvo retardante de llama libre de halógenos marca HT-E (elaborado con sales de amonio). Los recubrimientos que tuvieron el mejor desempeño fueron los siguientes: esmalte sintético negro mezclado con polvo de bórax; pintura intumescente marca Venier; y esmalte sintético negro mezclado con arena.

\section{Introducción.}

En la Ciudad de Córdoba, Argentina, se ha desarrollado el Proyecto de Investigación Orientado en Red titulado "Desarrollo tecnológico de tejas con materiales reciclados para viviendas" en los años 2011 y 2012, por un equipo de trabajo integrado por el CEVE (Centro Experimental de Vivienda Económica) dependiente del CONICET (Consejo Nacional de Investigaciones Científicas y Técnicas) y de AVE (Asociación de Vivienda Económica) conjuntamente por el CINTEMAC (Centro de Investigación, Desarrollo y Transferencia de Materiales y Calidad de la Universidad 
Tecnológica Nacional, Facultad Regional Córdoba), y el apoyo del Laboratorio de Estructuras de la Universidad Nacional de Córdoba.

El objetivo general fue colaborar en la descontaminación del medio ambiente y realizar una propuesta para la solución del déficit habitacional de nuestro país. El objetivo específico fue el desarrollo de componentes constructivos sustentables desde los puntos de vista ecológico, técnico y económico. Este componente es una teja elaborada con caucho y plástico reciclado fabricada por un proceso de termomoldeo.

En nuestro país hay escasa conciencia sobre la necesidad del reciclado, se estima que el $70 \%$ de la basura es reciclable, pero sólo un $10 \%$ de esta cantidad se recupera e ingresa nuevamente al ciclo productivo (Agencia Córdoba Ambiente 2001). La generación de basura en nuestro país es de $1 \mathrm{~kg}$ por persona por día. Dentro de los residuos sólidos urbanos, existe como tal una gran cantidad de neumáticos fuera de uso (NFU) que generan un grave problema al medio ambiente por las dificultades para realizar una correcta disposición final de los mismos. Según lo informado por el Instituto Nacional de Tecnología Industrial (INTI), "Se estima que en nuestro país la generación de neumáticos fuera de uso supera las 100.000 toneladas anuales" (INTI 2010). El problema que generan los neumáticos en los basurales es el gran volumen que ocupan y el largo tiempo de degradación (600 años aproximadamente), creando un hábitat propicio para la proliferación de mosquitos transmisores del dengue y roedores.

Los plásticos son otros residuos que ocupan un lugar importante dentro de los residuos sólidos urbanos ya que constituyen el 13,3\% del total de los residuos urbanos (en peso) lo que equivale al $30 \%$ del total de volumen en la Argentina (CEAMSE 1992). Su principal uso es el de embalajes (bolsas y láminas de plástico, geomebranas, contenedores, etc.).

Una de las premisas del desarrollo sostenible es evitar el agotamiento de los recursos, mediante el reciclado y la recuperación de los residuos.

Antecedentes internacionales de utilización de partículas de caucho y plástico reciclado en elementos constructivos: se destacan las experiencias realizadas en Brasil de tejas desarrolladas con embalajes de larga vida, compuestos por una lámina de cartón y plásticos (Fiorelli et al. 2009), las chapas para techo elaboradas con fibras de nylon que simulan tejas, desarrolladas en E.E.U.U. (Bacon 2005), los componentes para techos patentados en Europa, elaborados con polietileno, polipropileno, caucho y áridos diversos (Boor 2009), la mezcla de bitumen proveniente de neumáticos en desuso con polietileno reciclado, para la ejecución de techados e impermeabilizantes, desarrollada en España (Navarro et al. 2010), los productos para techos que simulan pizarras o tejas de arcilla, elaborados con polietileno de ultra baja densidad como ligante y un material de carga que puede comprender productos de caucho reciclado tales como EPDM (monómero de etileno propileno dieno) y SBR (caucho de estireno butadieno), patentados por Edson (Edson 2004). También las tejas curvas elaboradas con caucho y plásticos, moldeadas por compresión, que poseen crestas y conectores para formar una sola pieza que cubre un techo, patentada por Meyer (Meyer and Edson 2004), el material compuesto por caucho reciclado, microesferas termoplásticas expandibles y aditivos convencionales, que se puede aplicar en tejas y otros productos, patentado por Degerman (Degerman 2002) y las tejas elaboradas con polvo de caucho y plásticos varios desarrolladas por Liu, Yang y Hao (Liu, Yang, and Hao 2010), entre otros. El análisis de estos ejemplos permitó tomar decisiones y definir el programa experimental en cuanto a dosificación, materiales constitutivos, procedimientos de elaboración, diseño, métodos de ensayo para determinación de propiedades físicas y químicas.

Con respecto al tratamiento ignifugo del componente desarrollado, se han experimentado diferentes productos conocidos en el mercado, que se aplican sobre materiales plásticos. No hay un retardante de llama universal dada la gran variabilidad de factores que intervienen en un incendio (Sierra Buezas 2010). 
El comportamiento en presencia del fuego de los materiales se puede examinar de diferentes modos, dependiendo de los estándares que deseamos tomar en consideración. En este trabajo se realizaron los ensayos bajo la Norma Internacional IEC 60695-2-1 1: 2013, de amplia aplicación en todo el mundo.

2 Materiales y proceso de elaboración.

Para la elaboración de las tejas se emplearon dos tipos de residuos:

- Plásticos: polietileno de baja densidad procedente de bidones y caños desechados y triturados, Figura 1.

- Caucho: procedente de neumáticos fuera de uso, también triturado, Figura 1.
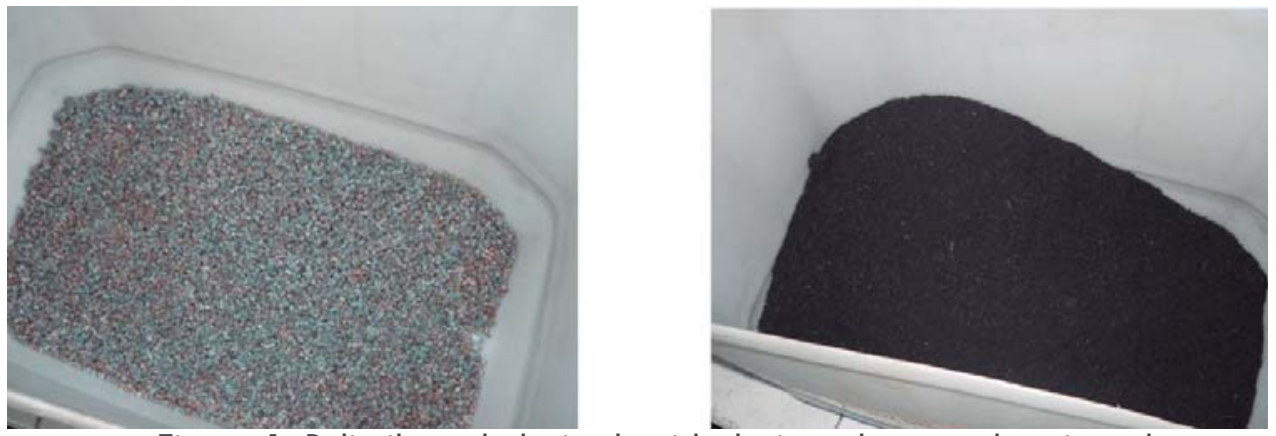

Figura 1: Polietileno de baja densidad triturado y caucho triturado

Las tejas se obtienen mediante un proceso de termo-moldeo con compactación utilizando un equipo de prensa con temperatura. Esta máquina especialmente diseñada para este proceso, cuenta con una prensa neumática, la cual es controlada por la manipulación de aire a presión (Figura 2). El aire es forzado en un tubo que se llena con el aire y se aplica con presión que hace que la prensa se desplace hacia abajo. Una vez que el recorrido de la prensa está terminado, el aire se evacua a través de las válvulas, los resortes mecánicos haciendo que la bomba se mueva de nuevo hacia arriba.

Para comenzar con el proceso, la mezcla conformada por las dos materias primas mencionadas anteriormente se ingresa a la tolva en estado sólido. Luego éstas, al pasar por el tornillo, son calentadas a medida que la mezcla avanza por varias zonas de calentamiento hasta el extremo final donde se encuentra el punto de mayor temperatura (alcanzado temperaturas entre 250-270 ${ }^{\circ} \mathrm{C}$ ). De ahí, el líquido viscoso obtenido se coloca en la matriz (molde), desparramando el material (Figura 2) que luego es sometido a un proceso de compactación (10 Tn) mediante el uso de la prensa neumática durante 4 minutos.
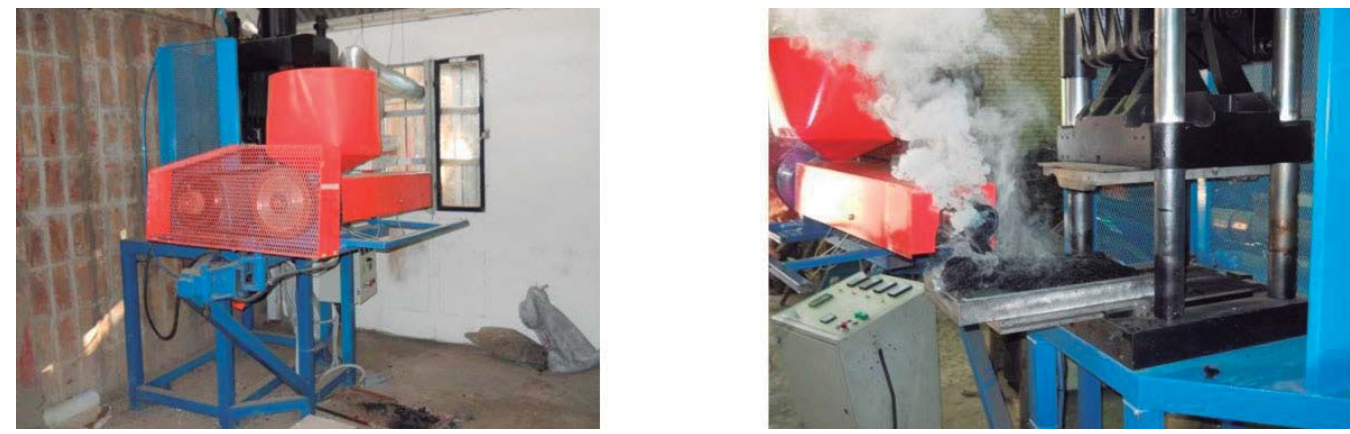

Figura 2: Equipamiento para fabricación de tejas, mezcla sobre matriz.

Luego la teja se desmolda y se lleva a un bastidor para su enfriamiento evitando deformaciones. Se le cortan las rebabas de material sobrante, y ya está lista para su uso (Figura 3).

Tamaño de la teja: longitud: 40,80 cm., ancho: 23,00 cm., espesor promedio: 1,5 cm.

Peso unitario: $1,7 \mathrm{Kg}$. 


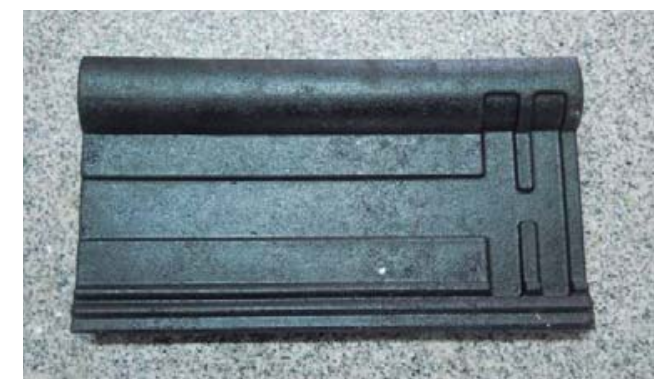

Figura 3: Teja elaborada a base de NFU y plásticos.

\section{Metodología.}

Para el desarrollo de la teja patrón, es decir sin recubrimiento de materiales retardantes de llama, se aplicó una metodología experimental consistente en la fabricación de probetas en las cuales se modificaron variables de a una por vez, tales como la dosificación de materiales, granulometrías, materiales constitutivos, procedimientos de elaboración, temperatura aplicada, presión mecánica y diseño morfológico.

Posteriormente se realizaron ensayos en laboratorio para establecer las propiedades técnicas de las tejas, y realizar ajustes en el proceso hasta alcanzar resultados que cumplan los estándares nacionales en cada aspecto. Las principales ventajas técnicas de estas tejas, según los ensayos realizados, son la elevada resistencia a la flexión y al impacto duro, baja conductividad térmica, baja absorción de agua e hinchamiento nulo por inmersión en agua.

Finalmente, se construyó un prototipo de vivienda en el predio del instituto de investigación, para evaluar aspectos de durabilidad, estanqueidad, facilidad de montaje, etc.

En una segunda etapa se buscó el mejoramiento del desempeño técnico del componente, concretamente en lo referido a la resistencia al fuego, puesto que la teja patrón no cumplía la normativa. Se realizaron ensayos con diversos recubrimientos con materiales retardantes de llama, bajo la Norma Internacional IEC 60695-2-1 1: 2013 denominada: Ensayo de inflamabilidad de alambre incandescente para productos finales (Sierra Buezas 2010).

Descripción del ensayo: La muestra a ensayar es el producto final (teja). El alambre incandescente se calienta a la temperatura requerida (en nuestro caso, se estableció en $575^{\circ} \mathrm{C}$ ) y se aplica durante 30 segundos en el área del producto donde el material plástico es más delgado. Luego se retira y se observa la muestra durante 30 segundos más.

Se evalúan los siguientes parámetros:

- $\quad$ Si se produce la ignición

- Si ocurre la ignición, cuánto tiempo demora en ocurrir

- El tiempo que tarda la extinción de las llamas

- Si la muestra es completamente consumida por las llamas

- Si el tejido debajo de la muestra se encendió por la caída de los desechos

La muestra pasa la prueba si:

a) No se enciende, 0

b) las llamas se extinguen dentro de los 30 segundos siguientes a la eliminación del hilo incandescente y el tejido por debajo no se enciende.

De este ensayo se obtienen dos valores:

-GWIT o temperatura de ignición y es la temperatura a la que la probeta se inflama con llamas durante 5 segundos o más;

-GWFI o índice de inflamabilidad es la temperatura a la que las llamas duran hasta 30 segundos. 
Se ensayaron las siguientes muestras:

1. Probeta patrón, sin recubrimiento con retardantes de llama.

2. Probeta con recubrimiento de esmalte sintético negro mezclado con Bórax. Este material, también llamado Borato de sodio o tetraborato de sodio ( $\mathrm{Na} 2 \mathrm{~B} 4 \mathrm{O} 7 \cdot 1 \mathrm{OH} 2 \mathrm{O})$, es un compuesto del boro y es considerado un material con propiedades ignífugas. Se mezcló con esmalte sintético negro, en una concentración de 7,5\%p/p.

3. Probeta con recubrimiento de esmalte sintético negro mezclado con residuos de pulido de porcelanato (RPP). Este material es un polvo compuesto por varios minerales, que se obtiene al pulir mosaicos de porcelanato. Se lo ha empleado por ser un material inorgánico y por ende no combustible. Se mezcló con esmalte sintético negro, en una concentración de 7,5\%p/p.

4. Probeta con recubrimiento de revoque plástico fino flexible. Este material está formado por un ligante tipo látex acrílico y sólidos (inorgánicos) de granulometría fina. Marca del producto utilizado: Revear.

5. Probeta con recubrimiento de pintura intumescente. Esta pintura, bajo la acción del calor desarrolla una espuma aislante de muy baja conductividad térmica protegiendo al material de la acción del fuego. Marca del producto utilizado: Venier.

6. Probeta con recubrimiento de esmalte sintético negro mezclado con arena. Este material es inorgánico, no combustible. Se mezcló con esmalte sintético negro, en una concentración de 45 $\% \mathrm{p} / \mathrm{p}$.

7. Probeta con recubrimiento de esmalte sintético negro mezclado con polvo retardante de llama libre de halógenos. Este material está elaborado con sales de amonio. Marca del producto utilizado: H.T.E., comercializado por la empresa Fullchem. Se mezcló con esmalte sintético negro, en una concentración de 7,5\%p/p.

Las probetas empleadas fueron recortes de tejas recicladas (caucho y polietileno). Se elaboraron 7 tipos de muestras comenzando por la denominación "patrón" (sin tratamiento), y luego se aplicaron recubrimientos de esmalte sintético mezclado con los diferentes materiales retardantes de llama. Los ensayos se hicieron por duplicado.

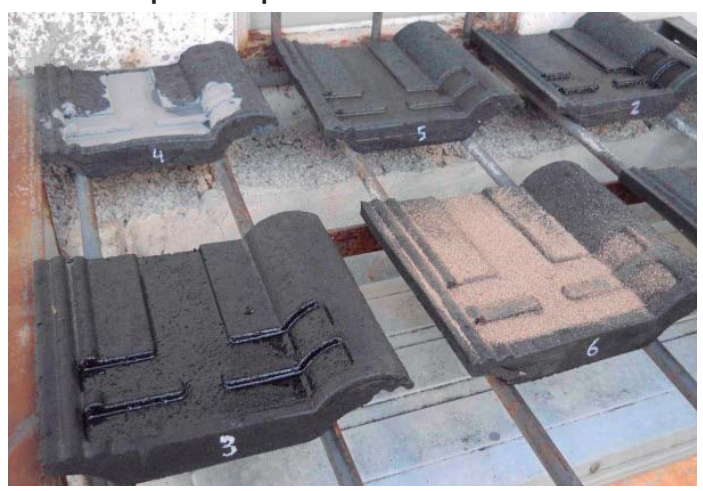

Figura 4: Probetas con recubrimientos diversos con materiales retardantes de llama.

El equipamiento empleado para realizar este ensayo fue el siguiente:

- Carro porta muestra con bajo nivel de rozamiento. El avance y retroceso del carro se realiza sobre de ruedas que se desplazan sobre perfiles.

- Filamento de NiCromo (aleación de níquel y cromo) de $4 \mathrm{~mm}$ de diámetro, con el formato especificado por la Norma. Se coloca sobre un soporte, al cual se aproxima el carro con la muestra. La alimentación es de 220VCA. La temperatura es monitoreada mediante una termocupla tipo 


\section{$\mathrm{K}(\varnothing 0.8 \mathrm{~mm})$.}

- Notebook con software específico donde se registran los tiempos de ignición y de extinción del fuego, y la temperatura alcanzada. El calentamiento es controlado mediante una placa Arduino UNO conectada a la PC.

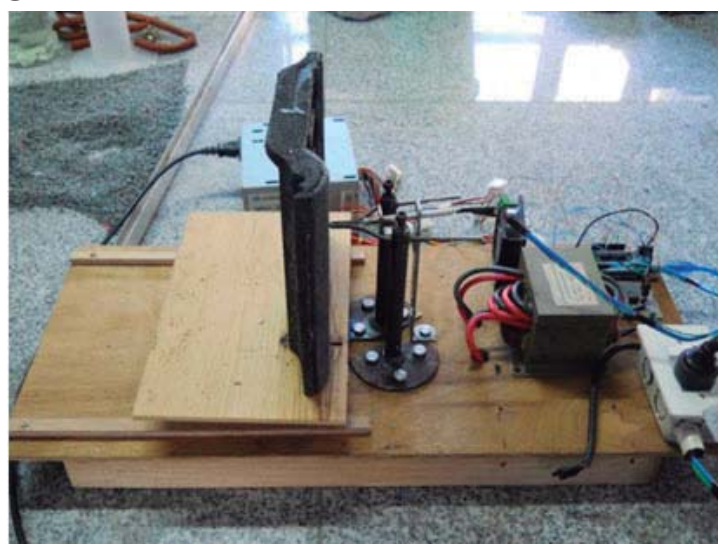

Figura 5: Equipamiento empleado para el ensayo.

Para comenzar, se realizaron pruebas de calentamiento del material para evaluar las condiciones de temperatura y observar cuál era la reacción del material. La temperatura de ignición de un material es la necesaria para que la sustancia empiece a arder y se mantenga la llama sin necesidad de añadir calor exterior. Influyen otros factores tales como la presión y la presencia de oxígeno.

Teniendo en cuenta la temperatura de ignición de los dos materiales constitutivos (de $350^{\circ} \mathrm{C}$ la del polietileno y de $465^{\circ} \mathrm{C}$ la del caucho) se decidió comenzar los ensayos aplicando calor hasta alcanzar la temperatura del que tiene el punto de ignición más bajo (o sea la del polietileno: $350^{\circ} \mathrm{C}$ ), con la cual no se produjo ignición del material; luego se fue aumentando gradualmente hasta $600{ }^{\circ} \mathrm{C}$, temperatura con la cual se produjo la ignición inmediata de la probeta sin tratamiento superficial. Se fue incrementando un valor de $50^{\circ} \mathrm{C}$ en cada una de las pruebas sucesivas. Finalmente se optó por realizar todos los ensayos a una temperatura de $575^{\circ} \mathrm{C}$.

En la siguiente Tabla se detallan los resultados obtenidos:

Tabla 1. Resultados obtenidos para los diferentes tratamiento superficiales con retardantes de llama.

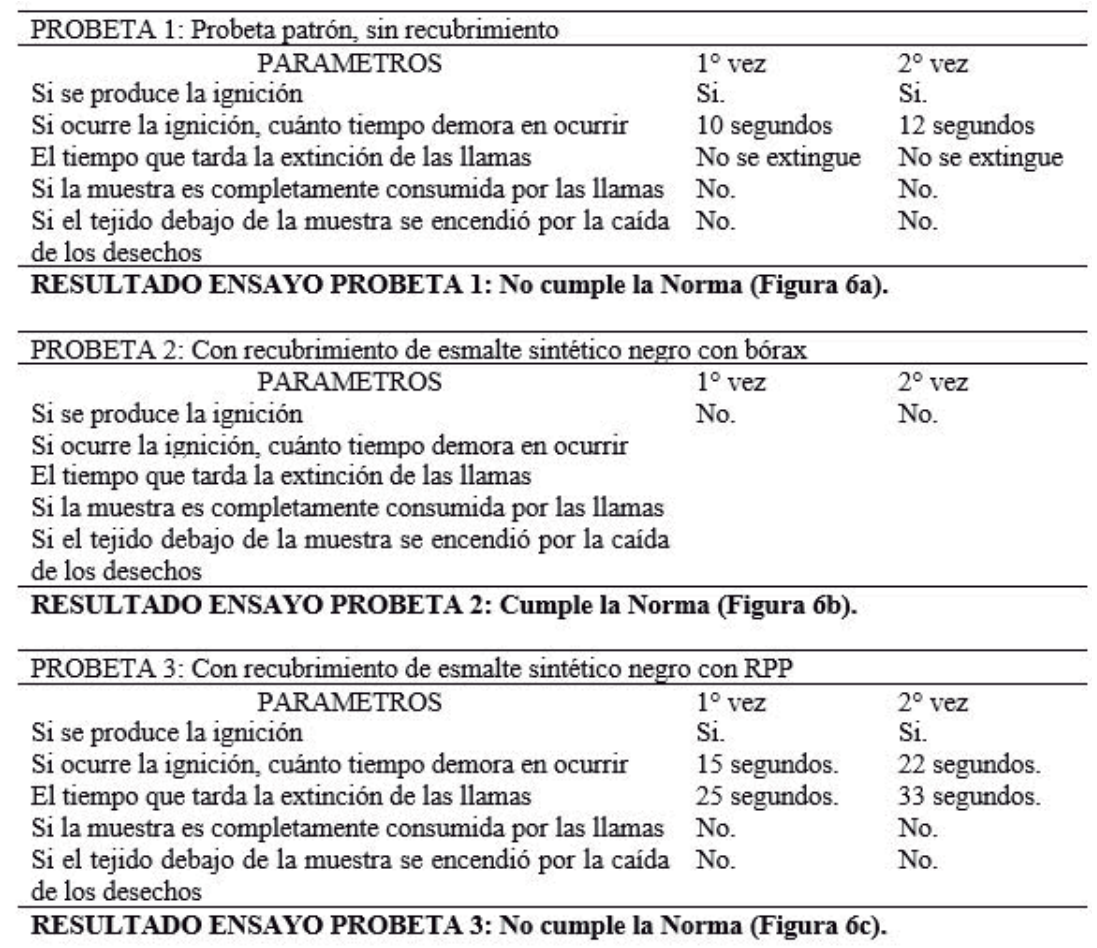




\begin{tabular}{|c|c|c|}
\hline \multicolumn{3}{|c|}{ PROBETA 4: Con recubrimiento de revoque plástico fino marca Revear } \\
\hline PARAMETROS & $1^{\circ} \mathrm{vez}$ & $2^{\circ} \mathrm{vez}$ \\
\hline Si se produce la ignición & Si. & Si. \\
\hline Si ocurre la ignición, cuánto tiempo demora en ocurrir & 22 segundos. & 23 segr \\
\hline El tiempo que tarda la extinción de las llamas & No auto extingue & No auto \\
\hline Si la muestra es completamente consumida por las llamas & No. & No. \\
\hline $\begin{array}{l}\text { Si el tejido debajo de la muestra se encendió por la caída } \\
\text { de los desechos }\end{array}$ & No. & No. \\
\hline
\end{tabular}

de los desechos

RESULTADO ENSAYO PROBETA 4: No cumple la Norma (Figura 6d).

\begin{tabular}{ccl}
\hline PROBETA 5: Con recubrimiento de pintura intumescente marca Venier \\
\hline PARAMETROS & $1^{\circ} \mathrm{vez}$ & $2^{\circ}$ vez \\
Si se produce la ignición & No. & No.
\end{tabular}

Si ocurre la ignición, cuánto tiempo demora en ocurrir

El tiempo que tarda la extinción de las llamas

Si la muestra es completamente consumida por las llamas

Si el tejido debajo de la muestra se encendió por la caída

de los desechos

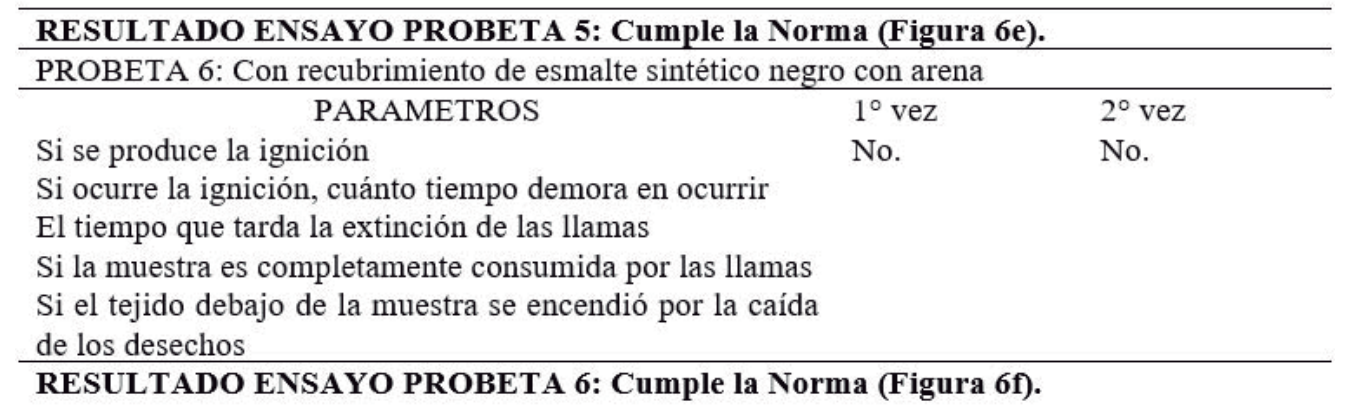

PROBETA 7: Con recubrimiento de esmalte sintético negro con polvo retardante de llama libre de halógenos marca HTE

PARAMETROS

$\begin{array}{ll}1^{\circ} \text { vez } & 2^{\circ} \text { vez } \\ \text { Si. } & \text { No. }\end{array}$

Si se produce la ignición

Si ocurre la ignición, cuánto tiempo demora en ocurrir

12 segundos.

El tiempo que tarda la extinción de las llamas

Si la muestra es completamente consumida por las llamas No.

Si el tejido debajo de la muestra se encendió por la caída No.

No.

de los desechos

RESULTADO ENSAYO PROBETA 7: No Cumple la Norma (Figura 6g).

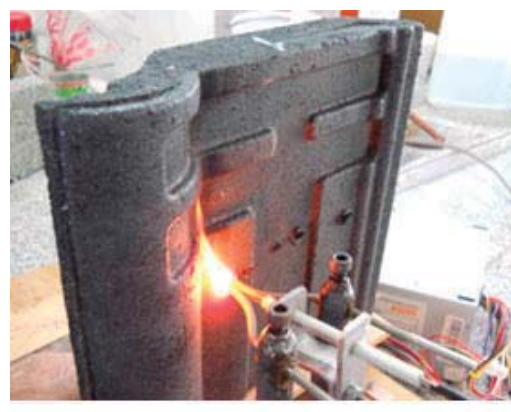

(a)

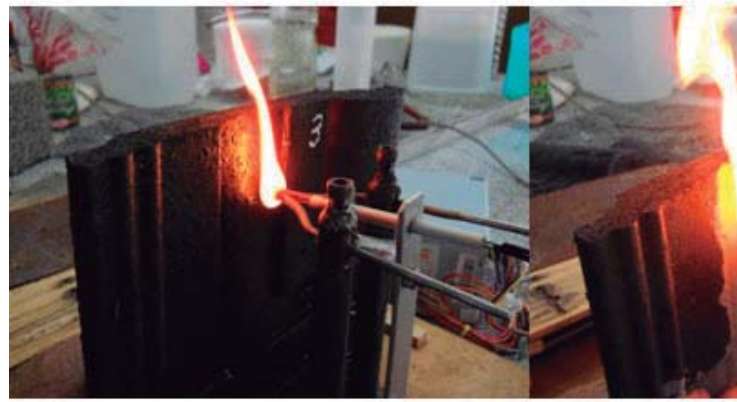

(c)

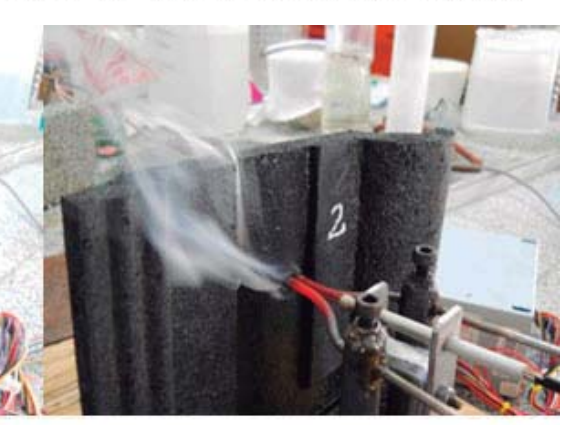

(b)

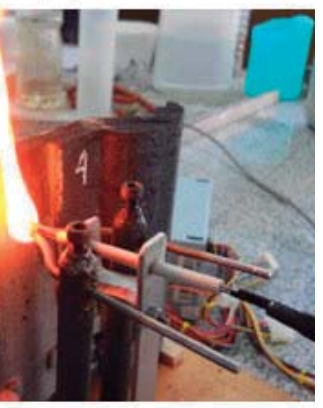

(d) 


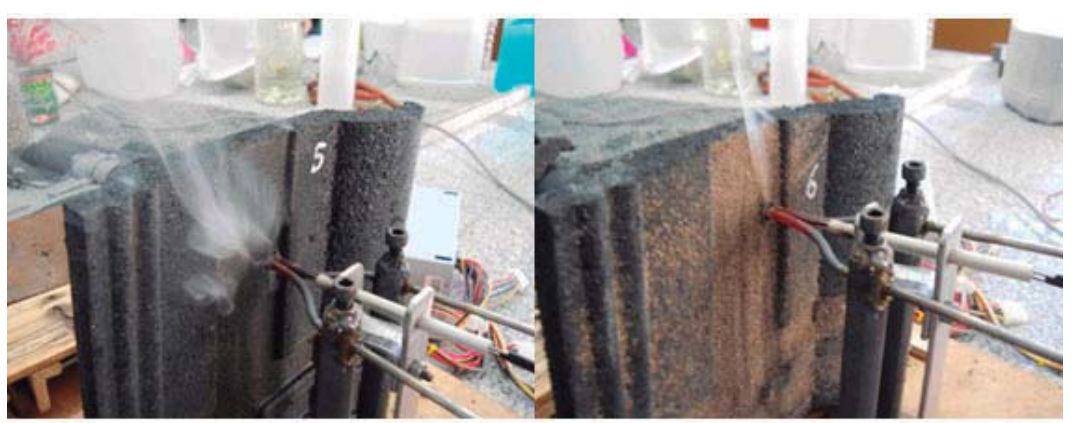

(e)

(f)

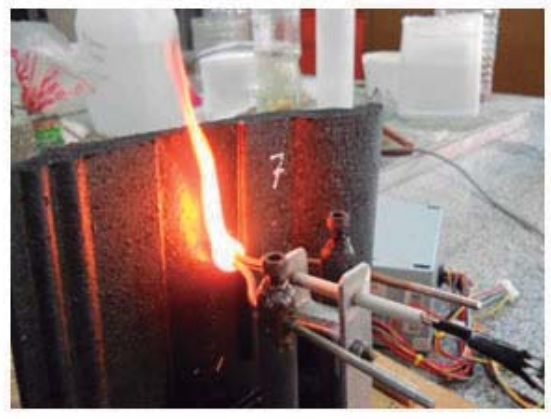

(g)

Figura 6. (a) probeta 1: sin recubrimiento, (b) probeta 2: con esmalte sintético y bórax, $\quad$ (c) probeta 3: con esmalte sintético y rpp, (d) probeta 4: con revoque fino flexible Revear, (e) probeta 5: con pintura intumescente Venier, (f) probeta 6: con esmalte sintético y arena, (g) probeta 7 con esmalte sintético y polvo retardante de llama libre de halógenos.

\section{Conclusiones}

Las tejas elaboradas con caucho y plástico reciclados sin un recubrimiento de materiales retardantes de llama son combustibles, por lo cual tienen un comportamiento al fuego inferior con respecto a otras tejas tradicionales como por ejemplo la teja cerámica o la de hormigón, las cuales son incombustibles. Sin embargo, las tejas con los recubrimientos retardantes de llama descriptos en este trabajo son resistentes al fuego: con esmalte sintético negro mezclado con bórax, con pintura intumescente marca Venier y con esmalte sintético mezclado con arena. Las tejas con estos tres tipos de recubrimiento cumplen con la Norma Internacional IEC 60695-2-1 1: 2013, sometidas al calor de un hilo incandescente hasta alcanzar una temperatura de $575{ }^{\circ} \mathrm{C}$. Por otro lado, a temperaturas mayores a $650{ }^{\circ} \mathrm{C}$ ninguna de las tejas desarrolladas es resistente al fuego, aún con recubrimientos con materiales retardantes de llama.

Las tejas con los recubrimientos descriptos en este trabajo resisten una temperatura mucho más alta que la de otros materiales que combustionan en la mayoría de los casos de incendios en el interior de las viviendas. Estos materiales de fácil combustión suelen ser la espuma de poliuretano de los colchones, que se encienden cuando alcanzan una temperatura de $150{ }^{\circ} \mathrm{C}$, los muebles de madera y las estructuras de madera, que se encienden cuando alcanzan una temperatura de 155 ${ }^{\circ} \mathrm{C}$ (en el caso de maderas blandas) y de $180^{\circ} \mathrm{C}$ (en el caso de maderas duras) y los textiles de algodón de cortinas, sillones y ropa, que se encienden cuando alcanzan una temperatura de $500^{\circ} \mathrm{C}$.

Teniendo en cuenta que las tejas se colocan sobre una estructura de madera de tipo tradicional, consistente de tirantes, alfajías y clavaderas, y cielorraso de terciado o machimbre (todos estos elementos de madera de pino, por lo general, por ser una madera de bajo costo y buena prestación) y siendo la temperatura de ignición de la madera de pino $155^{\circ} \mathrm{C}$, se deduce entonces que en caso de producirse un incendio, ardería primero la estructura de madera, la cual colapsaría antes que el fuego consuma a las tejas, las cuales comenzarían a arder a los $600^{\circ} \mathrm{C}$.

Comparando el comportamiento frente al fuego entre una cubierta con tejas elaboradas con plástico y caucho reciclado con una cubierta con tejas de tipo tradicional (de hormigón o cerámi- 
cas) se podría decir que en cualquiera de los tres casos, lo que colapsa primero es la estructura de madera, antes que las tejas se vean afectadas (en los casos que los incendios se hayan originado en el interior de las viviendas). De hecho, en la mayoría de los casos los incendios en las viviendas se originan en el interior de las mismas, ocasionados en general por un brasero, un accidente en la cocina, o un desperfecto eléctrico. En menor proporción los incendios son originados en el exterior de las viviendas, en general ocurre cuando las viviendas están ubicadas dentro de un bosque con riesgo de incendio, y raramente son ocasionados por fuegos artificiales.

La conclusión principal de este trabajo es que aplicando un recubrimiento apropiado de materiales retardantes de llama, es posible utilizar las tejas desarrolladas con caucho y polietileno reciclado, cumpliendo la Norma vigente en nuestro país. De esta manera, se puede producir un elemento constructivo ecológico y con ventajas técnicas tales como una mayor resistencia a la flexión y al granizo, menor peso específico y menor absorción de agua, respecto a otros elementos constructivos tradicionales tales como la teja cerámica o la de hormigón.

\section{Referencias.}

Agencia Córdoba Ambiente. 2001. Programa Córdoba Limpia. Gobierno de Córdoba.

Bacon, F. 2005. "Roofing Materials Made with Nylon Fiber Composites.". US20050170141 A1.

Boor, B. 2009. "Composite Material Roofing Structure.". WO 2009152213 A1

CEAMSE. 1992. "Publicaciones Periódicas."

Degerman, R. 2002. "Procedimiento Para Reutilizar Caucho Vulcanizado Y Productos Obtenidos.". 935636.

Edson, G. 2004. "Waterproof, Durable Products Made from Recycled Rubber Products.". US6703440.

Fiorelli, J., J. A. B. Morceli, R. I. Vaz, and A. A. Dias. 2009. "Avaliação Da Eficiência Térmica de Telha Reciclada À Base de Embalagens Longa Vida." Revista Brasileira de Engenharia Agrícola $\mathrm{E}$ Ambiental 13(2):204-9.

INTI. 2010. "Argentina Comienza a Reciclar Neumáticos Fuera de Uso." Noticiero Tecnológico Semanal No218.

Liv, Y., W. M. Yang, and M. F. Hao. 2010. "Research on Mechanical Performance of Roof Tiles Made of Tire Powder and Waste Plastic." Pp. 329-32 in Advanced Polymer Processing, vol. 87, Advanced Materials Research. Trans Tech Publications.

Meyer, L. and G. Edson. 2004. "Curved Roofing Tile Structure.". US6706366 B2.

Navarro, F. J., P. Partal, F. J. Martínez-Boza, and C. Gallegos. 2010. "Novel Recycled Polyethylene/ground Tire Rubber/bitumen Blends for Use in Roofing Applications: Thermo-Mechanical Properties." Polymer Testing 29(5):588-95.

Sierra Buezas, N. 2010. "Guía Plásticos Y Fuego." Programa de Fomento de La Innovación En Institutos Tecnológicos. 